Open Access

\title{
Cystathionine- $\gamma$-lyase expression is associated with mitochondrial respiration during sepsis-induced acute kidney injury in swine with atherosclerosis
}

Tamara Merz $^{1 *}$ (D, Martin Wepler ${ }^{1,2}$, Benedikt Nußbaum ${ }^{2}$, Josef Vogt ${ }^{1}$, Enrico Calzia ${ }^{1}$, Rui Wang $^{3}$, Csaba Szabo $^{4,5}$, Peter Radermacher ${ }^{1}$ and Oscar McCook ${ }^{1}$

\author{
* Correspondence: tamara.merz@ \\ uni-ulm.de \\ ${ }^{1}$ Institut für Anästhesiologische \\ Pathophysiologie und \\ Verfahrensentwicklung, \\ Universitätsklinikum Ulm, \\ Helmholtzstrasse 8-1, 89081 Ulm, \\ Germany \\ Full list of author information is \\ available at the end of the article
}

\begin{abstract}
Background: Sepsis is associated with disturbed glucose metabolism and reduced mitochondrial activity and biogenesis, ultimately leading to multiple organ dysfunction, e.g., acute kidney injury (AKI). Cystathionine- $\gamma$-lyase (CSE), the major cardiovascular source of endogenous $\mathrm{H}_{2} \mathrm{~S}$ release, is implicated in the regulation of glucose metabolism and mitochondrial activity through a PGC1a-dependent mechanism, and critical for kidney function. Atherosclerosis is associated with mitochondrial dysfunction and reduced CSE expression. Thus, the aim of this post hoc study was to test the hypothesis whether there is an interplay between CSE expression and kidney dysfunction, mitochondrial activity, and oxidative/nitrosative stress in porcine septic AKI with underlying coronary artery disease.

Methods: This study is a post hoc analysis of material from anesthetized and instrumented swine with a high fat diet-induced hypercholesterolemia and atherosclerosis undergoing faecal peritonitis-induced septic shock or sham procedure and intensive care (comprising fluid resuscitation and continuous i.v. noradrenaline (NoA) infusion) for $24 \mathrm{~h}$. Glucose metabolism was quantified from blood ${ }^{13} \mathrm{C}_{6}$-glucose and expiratory ${ }^{13} \mathrm{CO}_{2} /{ }^{12} \mathrm{CO}_{2}$ isotope enrichment during ${ }^{13} \mathrm{C}_{6}$-glucose infusion. Mitochondrial activity was determined by high-resolution respirometry. CSE and PGCla expression, as well as nitrotyrosine formation and albumin extravasation, were quantified by immunohistochemistry of formalin-fixed kidney paraffin sections.
\end{abstract}

Results: Sepsis was associated with lactic acidosis $(p=0.004)$ and AKI ( $50 \%$ fall of creatinine clearance $(\mathrm{CrCl}), p=0.019$ ). While both whole-body glucose production ( $p=$ $0.004)$ and oxidation $(p=0.006)$ were increased, kidney tissue mitochondrial respiration was reduced $(p=0.028)$, coinciding with decreased CSE $(p=0.003)$ and PGC1a $(p=0$. $003)$ expression. Albumin extravasation $(p=0.011)$ and nitrotyrosine formation $(p=0$. 008) were increased in septic kidneys.

Conclusions: Sepsis-induced AKI is associated with disturbed mitochondrial respiration and biogenesis, which may be aggravated by oxidative and nitrosative stress. Our results confirm previous data in murine septic shock and porcine hemorrhage and resuscitation on the crucial role of CSE for barrier integrity and kidney function.

Keywords: Peroxisome proliferator-activated receptor gamma coactivator 1-a, Barrier dysfunction, Oxidative stress, Co-morbidity, Glucose utilization, Hyperlactatemia 


\section{Background}

Septic acute kidney injury (AKI) is characterized by an acute decrease in renal function coinciding with relatively normal histologic morphology [1-5]. The severity of septic AKI is related to vascular leakage [1], derangements in glucose metabolism [6], and reduced mitochondrial activity $[7,8]$. Hydrogen sulfide $\left(\mathrm{H}_{2} \mathrm{~S}\right)$, an important "gaseous mediator," has been implicated in all the abovementioned: kidney function, vascular regulation, barrier function, glycemic control, and the mitochondria. Cystathionine- $\gamma$-lyase (CSE), the major enzymatic source for endogenous $\mathrm{H}_{2} \mathrm{~S}$, is constitutively expressed in the kidney and has been shown to be critical for kidney function $[9,10]$ as its "abundant" expression is associated with improved glomerular filtration in human transplant patients [11]. We recently demonstrated that CSE expression correlated with maintained creatinine clearance $(\mathrm{CrCl})$ and reduced vascular leakage in resuscitated murine polymicrobial septic shock [1].

CSE has also been shown to play a role in regulating glucose metabolism and mitochondrial function through a PGC1 $\alpha$-dependent mechanism $[8,12]$. $\mathrm{CSE}^{-/-}$mice displayed reduced gluconeogenesis, which was reversed by exogenous administration of $\mathrm{H}_{2} \mathrm{~S}$, through the upregulation of PGC1 $\alpha$ [12]. In addition, we recently demonstrated the inverse relationship, suggesting a regulatory loop; in hyperglycemic septic mice, CSE protein expression was downregulated concomitant with reduced PGC1 $\alpha$ levels and mitochondrial respiratory activity in both coupled (maximum oxidative phosphorylation (OxPhos)) and uncoupled (maximum capacity of the electron transfer system) states [8]. Impaired renal mitochondrial function, through its production and release of free radicals, may further aggravate organ injury during sepsis [13]. $\mathrm{H}_{2} \mathrm{~S}$ is a mitochondrial electron donor and a free radical scavenger [14] and has been demonstrated to attenuate AKI in pre-clinical ischemia/reperfusion models [9]. Its role in sepsis, however, is ambivalent: In rodent endotoxemia or sepsis, $\mathrm{H}_{2} \mathrm{~S}$ was reported to attenuate $[15,16]$ or aggravate [17] kidney dysfunction and/or injury.

Atherosclerosis is a common confounding factor in the management of sepsis, increasing mortality [18], which is often not incorporated by the use of naive/young animal models [9]. We recently reported that atherosclerotic pigs with coronary artery disease subjected to sepsis developed impaired cardiac function, which coincided with decreased CSE expression and increased nitrotyrosine formation $[19,20]$. Thus, the aim of this study was to test the hypothesis whether there is an interplay between CSE expression and kidney dysfunction, mitochondrial activity, and oxidative/nitrosative stress in porcine septic AKI with underlying co-morbidity. The used swine strain, "familial hypercholesterolemia Bretoncelles Meishan" (FBM), is characterized by coronary artery disease due to an atherogenic diet. FBM animals are known to exhibit significantly higher cholesterol levels compared to healthy swine of the same age [21-23] and present the biomarker pattern of hypercholesterolemia: increased oxidative stress and lower blood levels of nitric oxide (NO) metabolites [23] reminiscent of patients with hypercholesterolemia-induced atherosclerosis [24]. In atherosclerosis, CSE has been shown to play an important role: its downregulation is associated with hypertension, cardiovascular pathology, coronary artery disease, and chronic kidney disease [20, 25]. Data reported are a post hoc analysis of material available from a previous study [26].

\section{Methods}

The study was approved by the University of Ulm Animal Care Committee and the Federal Authorities for Animal Research. The experiments were performed in adherence to the National Institute of Health Guidelines on the Use of Laboratory Animals 
and the European Union "Directive 2010/63/EU on the protection of animals used for scientific purposes" and authorized by the federal authorities for animal research of the Regierungspräsidium Tübingen (approved animal experimentation number: 1024), Baden-Württemberg, Germany, and the Animal Care Committee of the University of Ulm, Baden-Württemberg, Germany. This is a post hoc study performed on available material from the vehicle-treated group of a previous study [26] and unpublished sham-operated animals studied simultaneously under the same protocol. The underlying atherosclerosis in the pig strain has previously been characterized in coronary vascular sections by our group $[19,20]$. Briefly, male castrated FBM (age 15-30 months, $69 \mathrm{~kg}(65-73 \mathrm{~kg}))$ with a high-fat diet-induced hypercholesterolemia and atherosclerosis [21] underwent polymicrobial septic shock $(n=8)$ induced by inoculation of autologous feces into the abdominal cavity, or sham procedure, i.e., abdominal saline injection $(n=5)$, and subsequently received intensive care therapy for $24 \mathrm{~h}$. Anesthesia and surgical instrumentation have been previously described in detail $[26,27]$. In brief, for all animals, anesthesia was induced with propofol and ketamine to allow endotracheal intubation and was maintained thereafter with continuous i.v. pentobarbitone and pancuronium and intermittent buprenorphine. Ventilator settings were fraction of inspired $\mathrm{O}_{2}\left(\mathrm{FiO}_{2}\right) 0.35$, positive endexpiratory pressure (PEEP) $10 \mathrm{cmH}_{2} \mathrm{O}$, tidal volume $8 \mathrm{~mL} / \mathrm{kg}$, respiratory rate 10 to 12 breaths/min adjusted to maintain arterial $\mathrm{PCO}_{2}=35$ to $40 \mathrm{mmHg}$, inspiratory (I)/expiratory (E) ratio 1:1.5, peak airway pressure $<40 \mathrm{cmH}_{2} \mathrm{O}$, and modified to I/ E ratio 1:1, and PEEP 12 or $15 \mathrm{cmH}_{2} \mathrm{O}$ if the ratio of arterial $\mathrm{O}_{2}$ partial pressure $\left(\mathrm{PaO}_{2}\right) / \mathrm{FiO}_{2}$ is $<300$ or $<200 \mathrm{mmHg}$, respectively [26]. The septic and sham pigs had the right jugular vein and carotid artery exposed for the insertion of a central venous catheter sheath and the placement of a balloon-tipped pulmonary artery catheter to measure central venous pressure (CVP) and a thermistor-tipped arterial catheter for blood pressure (mean arterial pressure (MAP)) recording and transpulmonary single indicator thermodilution-cardiac output measurement. Ringer's solution was continuously infused as maintenance fluid $(10 \mathrm{~mL} /(\mathrm{kg} \mathrm{h}))$ [20].

\section{Experimental protocol}

Atherogenic diet (1 kg daily, 1.5\% cholesterol, $20 \%$ bacon fat) was fed for at least 9 months prior to the experiments. Post anesthesia and surgical instrumentation, the supernatant $(3 \mathrm{~mL} / \mathrm{kg})$ of $1.0 \mathrm{~g} / \mathrm{kg}$ autologous feces incubated in $500 \mathrm{~mL} 0.9 \%$ saline for $12 \mathrm{~h}$ at $38{ }^{\circ} \mathrm{C}$, or saline only as sham procedure, was injected into the abdominal cavity via the abdominal drainage tubes. Hydroxyethyl starch $(10 \mathrm{~mL} /(\mathrm{kg} \mathrm{h})), 5 \mathrm{~mL} /$ $(\mathrm{kg} \mathrm{h})$ if CVP or PAOP was $>18 \mathrm{mmHg}$, allowed maintaining hyperdynamic hemodynamics. If necessary, norepinephrine was infused and titrated to maintain MAP at baseline values (not further increased if the heart rate was $\geq 160$ beats $/ \mathrm{min}$ to avoid tachycardia-induced myocardial ischemia) [26]. Twenty-four hours after the induction of fecal peritonitis, anesthesia was further deepened and animals were sacrificed with potassium chloride [20]. At the end of the experiment, the total amount of NoA given to the animal was documented. This amount was then normalized to the duration of the experiment and body weight of the animal to be able to compare averaged NoA infusion rates between the individual animals. 


\section{Measurements and calculations}

Hemodynamics, systemic and pulmonary gas exchange (arterial and mixed venous blood gases), creatinine, and renal glucose, lactate, and hemoglobin concentrations have been described previously in the original publication [26]. Using a steady-state approach, endogenous glucose production was calculated as the difference between the rate of appearance of stable, non-radioactively labeled $1,2,3,4,5,6-{ }^{13} \mathrm{C}_{6}$-glucose during continuous intravenous isotope infusion minus the exogenous glucose infusion rate after gas chromatography-mass spectrometry assessment of plasma isotope enrichment. Direct, aerobic glucose oxidation was derived from the mixed expiratory ${ }^{13} \mathrm{CO}_{2}$ isotope enrichment measured using non-dispersive infrared spectrometry and corrected for the plasma isotope ratio and $\mathrm{CO}_{2}$ production $[23,28]$. Urinary and renal blood creatinine levels were analyzed to calculate creatinine clearance; renal venous NGAL, TNF $\alpha$, and IL-6 levels were assessed as previously described $[23,26]$.

\section{Histopathology and immunohistochemistry}

For this experiment on the kidney, we selected the pig in contrast to the mouse, because pigs, monkeys, and humans share multilobular, multipapillary kidneys in contrast to rodent kidneys, which are unilobular and unipapillary. Furthermore, in rodents, the urine empties directly into the renal pelvis, whereas in pigs and humans, urine empties into a branched caliceal network that distributes to the renal pelvis. The intricate system of interlobar and segmented arteries, that provides blood flow to numerous kidney lobes in humans and pigs, is not present in rodents and dogs because they do not have the multiple medullary pyramids [29]. As a consequence, kidney ischemic injury in rodents leads to extensive necrosis of proximal tubules. In humans, in contrast, "frank tubular necrosis" is infrequent, less pronounced, and only patchy if present at all $[9,30]$.

Post-mortem, pyramid-shaped kidney samples comprising the kidney cortex, medulla, and renal papilla were fixed in formalin (fixation identical for all samples), dehydrated, and embedded in paraffin blocks. Paraffin sections $(3-5 \mu \mathrm{m})$ were cut, deparaffinized in xylene, and rehydrated with a graded series of ethanol to deionized water. Histopathological examination of hematoxylin-eosin-stained specimens was performed by an experienced pathologist blinded for the sample grouping [26]. Histopathological alterations were analyzed for the degree of "glomerular tubularization," dilatation of Bowman's space, and swelling of Bowman's capsule, cellular edema of the proximal tubule, distal tubular dilatation and elongation, tubular protein cylinders, and tubular necrosis as described in detail previously [26].

For immunohistochemistry, the slide sections containing sham and septic tissue were analyzed concurrently and included both negative and positive controls. After heatinduced antigen retrieval in citrate $\mathrm{pH} 6$, the slides were blocked with $10 \%$ normal sera (Jackson ImmunoResearch) before incubating in primary antibody $\left(1^{\circ} \mathrm{ab}\right.$, antinitrotyrosine (Millipore)), CSE: anti-CTH (Abnova), anti-PGC1 $\alpha$ (Novus), and anti-pig albumin (Abcam)). Primary antibody detection was performed by Dako REAL detection system (anti-mouse, anti-rabbit; alkaline phosphatase conjugated) and visualized with red chromogen (Dako REAL; Dako) followed by counterstaining with hematoxylin (Sigma). The slides were visualized using a Zeiss Axio Imager A1 microscope with a $\times 10$ objective. 
Quantification for intensity was performed on multiple $800,000-\mu \mathrm{m}^{2}$ sections using the AxioVision 4.8 software (Zeiss) [10]. Data are presented as densitometric sum red [20]. The obtained densitometric values for CSE were compared and correlated $(p=0.001)$ with the values obtained by western blotting (data shown in Additional file 1). It is well established in the literature that densitometric analysis of colorimetric immunohistochemical staining is as acceptable a method as western blotting for protein measurement [31-33]. In contrast to western blot, the IHC evaluation of the tissue allows identification of the physical topography and protein expression in different cell types.

\section{Mitochondrial respiration}

Mitochondrial respiratory activity was determined via high-resolution respirometry with a Clark-electrode-based system (Oxygraph 2k, OROBOROS Instruments Corp., Innsbruck, Austria) as described previously [34, 35]. Fresh postmortem kidney samples were collected in Custodiol (Franz Köhler Chemie) and mechanically homogenized in respiration medium (MIR05; $0.5 \mathrm{mM}$ EGTA, $3 \mathrm{mM} \mathrm{MgCl} 2 \cdot 6 \mathrm{H}_{2} \mathrm{O}, 60 \mathrm{mM}$ lactobionic

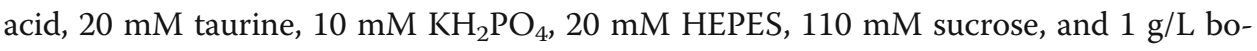
vine serum albumin), and $2 \mathrm{mg}$ of tissue was added to the Oxygraph chamber. The chambers were oxygenated to an $\mathrm{O}_{2}$ concentration of $400 \mu \mathrm{M}$. By the addition of a defined sequence of substrates and inhibitors, various states of mitochondrial function could be assessed. Ten micromolar cytochrome $\mathrm{c}$ was added to reactivate mitochondria after homogenization. Complex I activity was determined after the addition of $10 \mathrm{mM}$ pyruvate and glutamate, and $5 \mathrm{mM}$ malate and ADP. Maximum OxPhos was evaluated after subsequent addition of $0.5 \mathrm{mM}$ octanoyl-carnitine and $10 \mathrm{mM}$ succinate; leak compensation was assessed after inhibition of the ATP-synthase by $2.5 \mu \mathrm{M}$ oligomycin, followed by stepwise titration of the uncoupling agent carbonyl cyanide-4-(trifluoromethoxy) phenylhydrazone (FCCP, final concentration $1.5 \mu \mathrm{M}$ ) to reach maximum respiratory activity of the electron transfer system (ETS) in the uncoupled state. The activity of complex II was determined in the uncoupled state by the addition of $0.5 \mu \mathrm{M}$ rotenone, an inhibitor of complex I. The measurement was finished after the addition of $5 \mu \mathrm{M}$ of the complex III inhibitor antimycin A [8].

\section{Statistical analysis}

Data are presented as median (quartiles). Data on physiology and renal blood gas analysis were analyzed with a two-way ANOVA and post hoc Tukey test for multiple comparisons. All other group differences were analyzed with the Mann-Whitney rank sum test after exclusion of normal distribution using the Kolmogorov-Smirnov test. Quantitative relations of pooled data sets from all experimental groups, between noradrenaline infusion and creatinine clearance, between noradrenaline infusion and mitochondrial activity, and between mitochondrial activity and creatinine clearance, were determined with Spearman's coefficient for non-linear relationships, and the data were fitted to an exponential decay or growth according to the general equation $f(x)=a \cdot e^{ \pm b x}$. Correlations between CSE expression and PGC1 $\alpha$ expression, albumin extravasation, nitrotyrosine formation, and mitochondrial activity as well as correlations between nitrotyrosine and mitochondrial activity were evaluated by measuring Pearson's coefficient of correlation for linear relationships. A non-linear model was used whenever a linear model 
was not statistically significant and/or a markedly higher coefficient of correlation suggested better fitting of the non-linear model. Due to the post hoc character of the study, the complexity of the experiment, and the high amount of parameters evaluated, unfortunately, not all values were available for all the animals. The actual $n$ for the individual data sets is given in the respective figure legend.

\section{Results}

\section{Physiological data}

Additional file 1: Table S1 displays systemic physiologic parameters. Norepinephrine requirements to maintain hemodynamics were significantly higher in the septic group (NoA $p=0.004$ ). Furthermore, there was evidence that the septic pigs developed lactic acidosis, systemically (Additional file 1: Table S1), as well as on the kidney level (Additional file 1: Table S2). Inflammatory cytokines TNF $\alpha$ and IL6, determined from the renal venous blood, were elevated in sepsis (Additional file 1: Table S2). Septic pigs increased their glucose production and oxidation over time (see Fig. 1), whereas glucose metabolism did not change in the sham pigs. Blood glucose levels did not differ between the groups.

\section{Histopathology}

Kidney histopathology in the septic animals showed only mild to moderate glomerular and tubular damage with very limited apoptosis and necrosis (see Table 1). Nevertheless, organ function was significantly impaired by sepsis (see Fig. 2a), as evinced by $50 \%$ reduced urine output ( $p=0.011), 40 \%$ elevated plasma creatinine $(p=0.011)$, and, consequently, $50 \%$ reduced creatinine clearance $(p=0.019)$. Renal vein NGAL levels were significantly elevated in sepsis (see Fig. 2a).

\section{Mitochondrial respiration}

Impaired kidney function coincided with significantly reduced mitochondrial activity in the coupled as well as in the uncoupled state (see Fig. 2a), linked to the reduced activity of complex II. There was a trend towards stronger coupling and higher Olg respiration in the mitochondria from the septic kidney (OxPhos/ETS $0.92(0.82 ; 1.02)$ vs. 0.71 (0.68; 0.86), $p=0.14 ; \mathrm{Olg} / \operatorname{ETS} 0.36(0.28 ; 0.53)$ vs. $0.22(0.20 ; 0.34), p=0.14)$.

Plotting $\mathrm{CrCl}$ and $\mathrm{OxPhos}$ as functions of noradrenaline infusion rates revealed a significant inverse relationship between kidney function and mitochondrial activity to

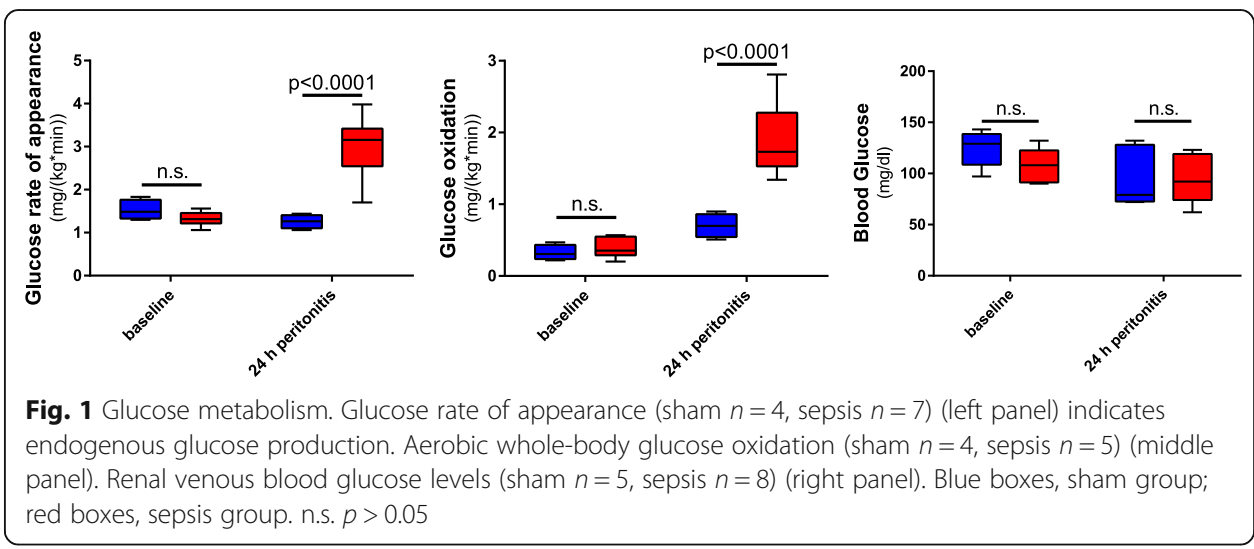


Table 1 Kidney histopathology score

\begin{tabular}{lll}
\hline & Sham & Sepsis \\
\hline \% glomerular tubularization & $2.5(0.5 ; 7.5)$ & $5.0(0 ; 13.8)$ \\
Tubular apoptosis/necrosis & 0 & 0 \\
Protein cylinders & $0(0 ; 0)$ & $1(0 ; 1)$ \\
Dilatation of Bowman's space & $0(0 ; 1)$ & $2(0 ; 3)$ \\
\hline
\end{tabular}

Glomerular tubularization, i.e., the herniation of proximal tubular epithelial cells into Bowman's capsule along the luminal surface of the capsule, is reported as the number of glomeruli showing herniation of the tubular epithelium in $\%$ of all glomeruli analyzed; all other data are the mean values of the scores of the five random sections for each item analyzed. Data are given as median (interquartile range)

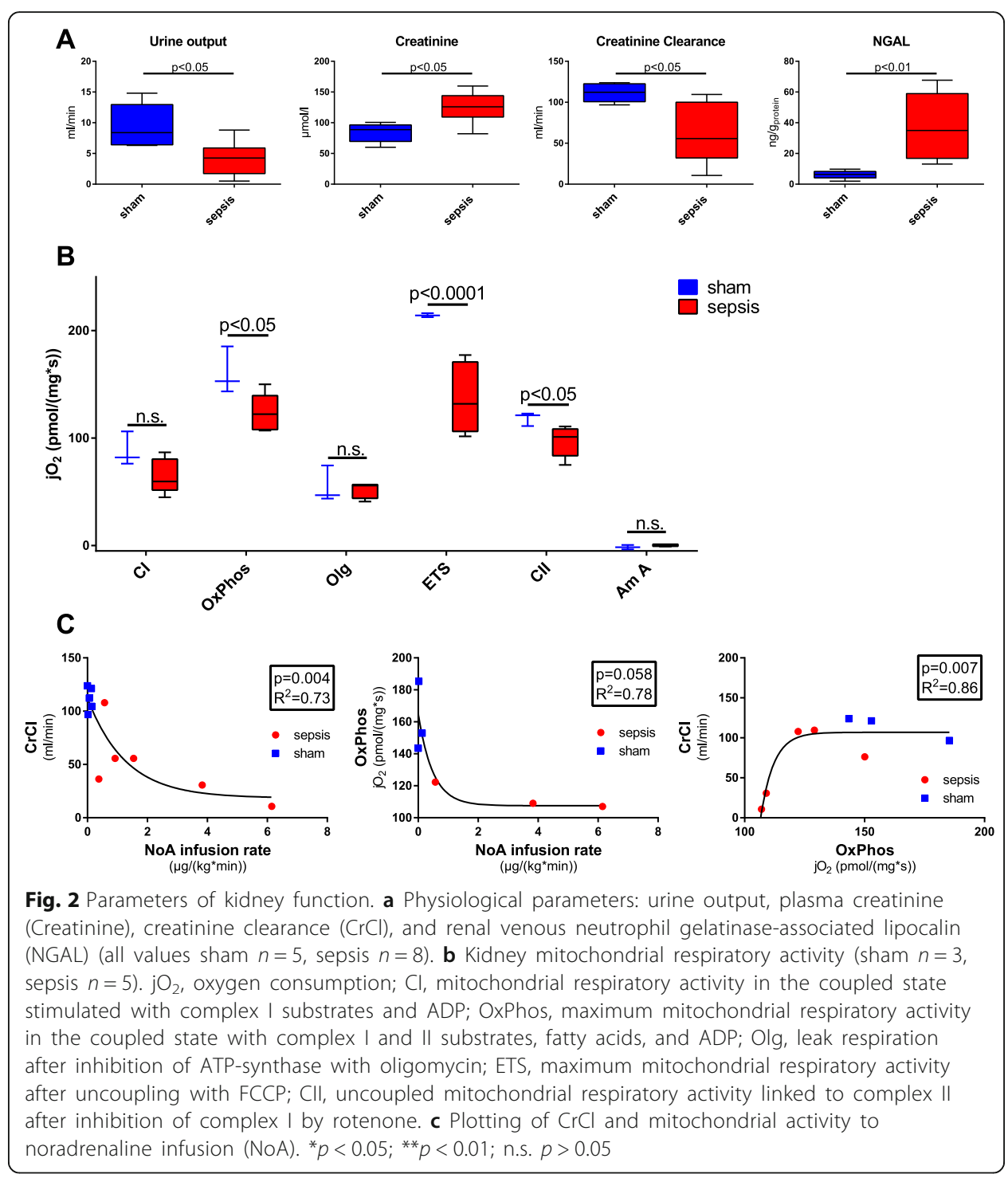


catecholamine requirements, respectively. Consequently, $\mathrm{CrCl}$ correlated with mitochondrial respiratory function.

\section{Protein expression}

Kidney immunohistochemistry (see Fig. 3) revealed significantly increased levels of nitrotyrosine and extravasated albumin in sepsis (Fig. 3a, b), concomitant with reduced CSE and PGC1 $\alpha$ expression (Fig. 3c, d). PGC1 $\alpha$ expression, mitochondrial respiratory activity, and creatinine clearance correlated with CSE expression. There was an inverse relationship with nitrotyrosine formation and albumin extravasation. Finally, kidney nitrotyrosine formation was correlated with the degree of coupling of the mitochondrial respiratory chain (OxPhos/ETS to nitrotyrosine $p=0.002)$ and inversely correlated with maximum mitochondrial respiratory activity in the coupled state (OxPhos) (correlations depicted in Fig. 4).

\section{Discussion}

We were able to confirm the initial hypothesis of an association between CSE expression and kidney dysfunction, mitochondrial activity, and oxidative/nitrosative stress in

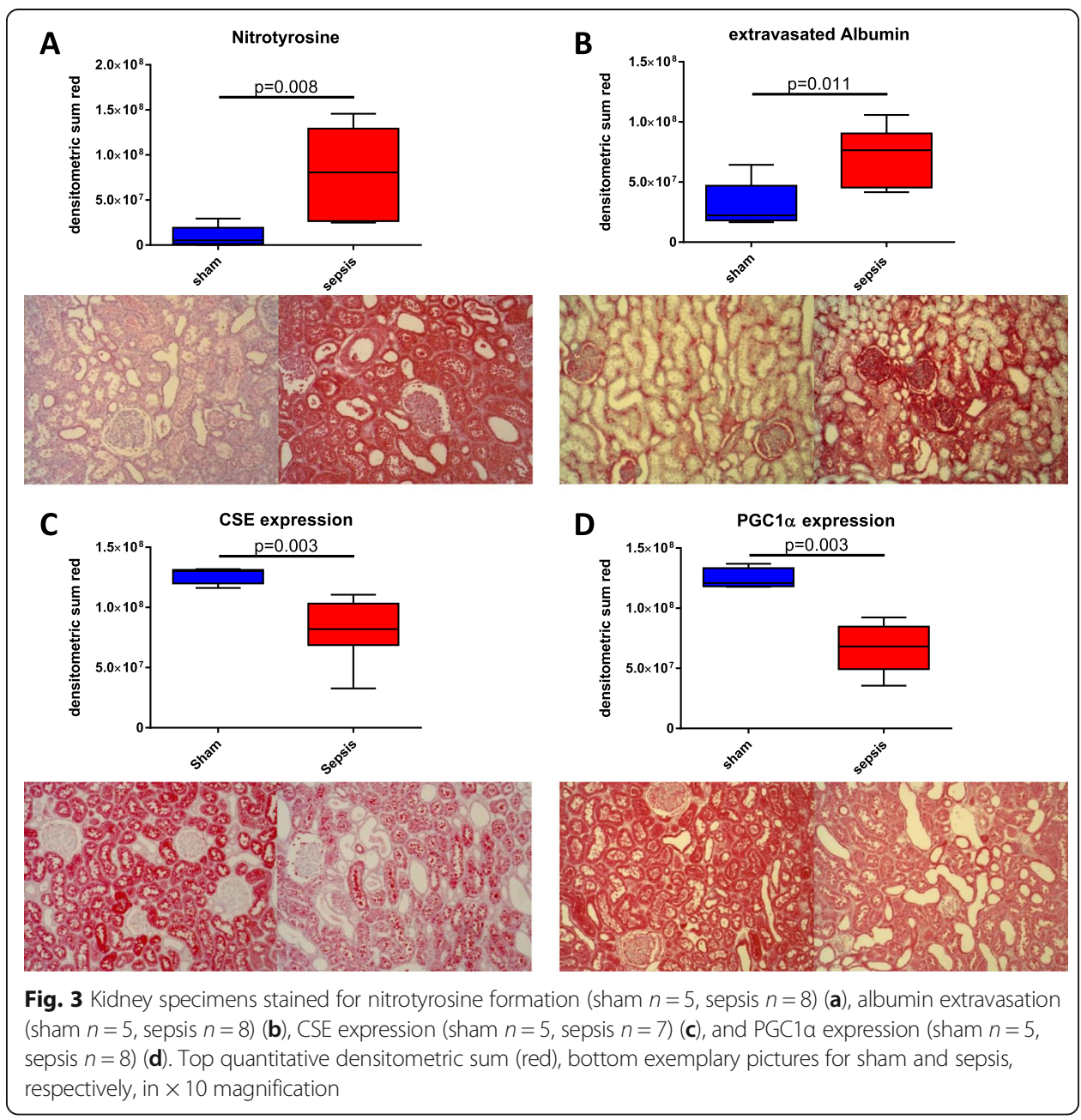


porcine septic AKI with underlying co-morbidity. The main findings of this study were (i) septic AKI accompanied by a marked drop in CSE expression which correlated with (ii) decreased glomerular filtration and (iii) reduced mitochondrial respiratory activity. Hyperlactatemia, metabolic acidosis, and enhanced glucose turnover were observed in the septic arm. $\mathrm{O}_{2}$ saturation and histopathological tissue injury did not differ between the sham and septic groups.

The lack of morphological changes associated with AKI, consistent with the literature $[2,3]$, led us to investigate renal protein expression. CSE is constitutively expressed in the kidney, and its expression correlates with the maintenance of glomerular filtration [1]. We were able to confirm these results; a sepsis-induced reduction of CSE expression was associated with kidney barrier dysfunction (indicated by the increased albumin extravasation; Fig. 3b, c) and thus contributed to the reduced glomerular filtration, as evinced in the impaired $\mathrm{CrCl}$ (Fig. 2a).

Furthermore, CSE has been reported to play a role in regulating glucose metabolism and mitochondrial function [8] through a PGC1 $\alpha$-dependent mechanism [12]. Consistent with these findings are reports that PGC1 $\alpha$ expression in the kidney of septic animals also has been shown to be reduced in proportion to the severity of the impaired

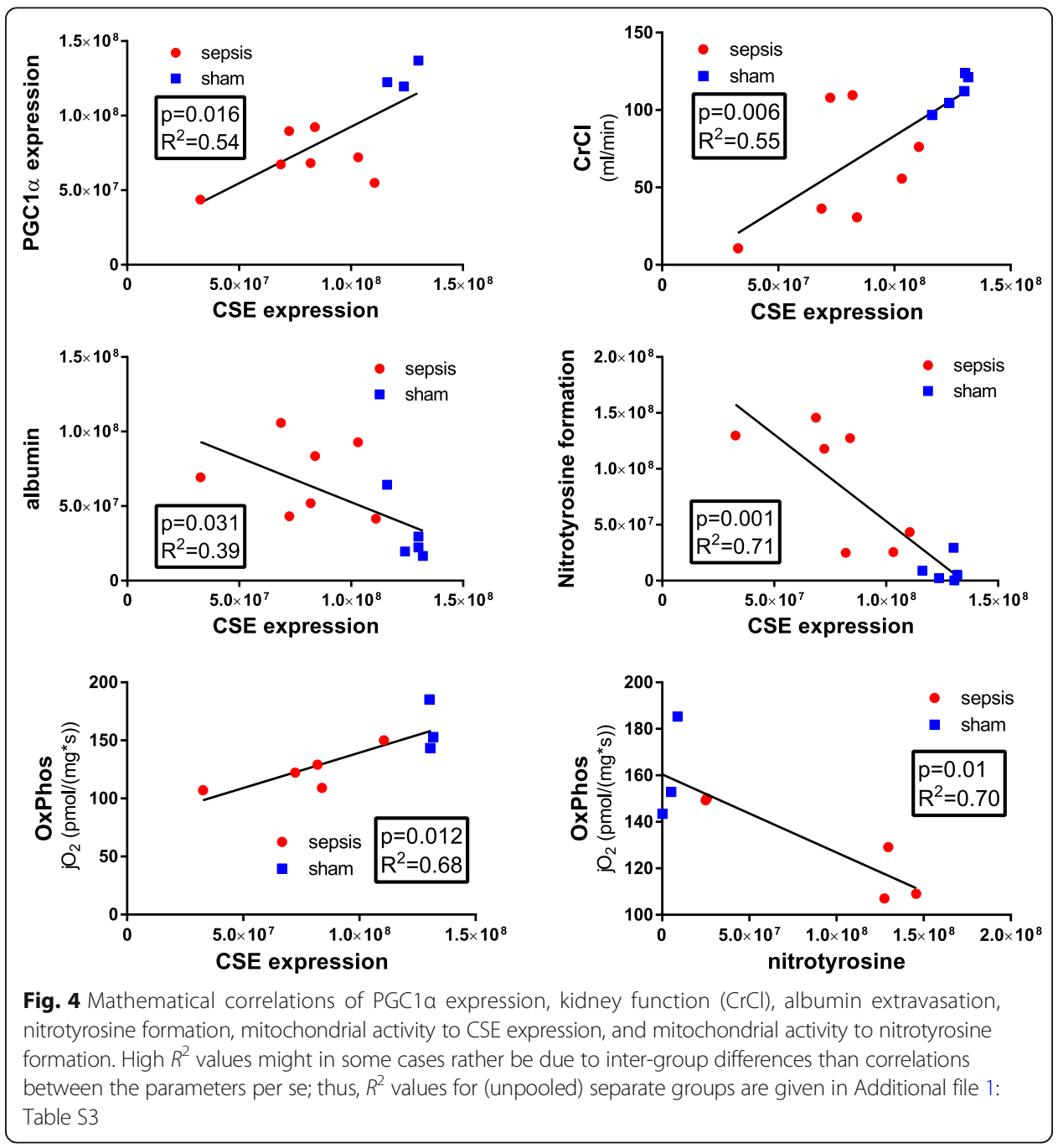


glomerular filtration rate [36]. This study was able to confirm a reduction of PGC1 $\alpha$ expression concomitant with the loss of CSE in the septic kidney (Fig. 3d), which correlated with decreased mitochondrial respiratory activity (Fig. 2b). These findings are consistent with reports of reduced mitochondrial respiratory activity in septic patients and animal models of sepsis $[7,8]$. Additionally, PGC1 $\alpha$ has been shown to regulate mitochondrial oxidative metabolism, and its overexpression protected podocytes in renal injury preventing mitochondrial dysfunction [37, 38].

Nitrotyrosine formation is a marker of injury and oxidative and nitrosative stress and was found to be markedly elevated in the septic in contrast to the sham kidney (Fig. 3a). Impaired oxidative phosphorylation (OxPhos) in podocytes results in increased ROS production and functional alterations which may account for disruption of the glomerular filtration barrier and reduced function $[39,40]$. The inverse correlation of nitrotyrosine formation with OxPhos (Fig. 4) implies a direct relationship of increased ROS/ RNS with impaired mitochondrial function, as previously reported by others [41-43]. In turn, the linear correlation of OxPhos/ETS ratio to nitrotyrosine formation suggests that in sepsis, the mitochondria themselves are at least partly responsible for the increased ROS/RNS production, probably due to the strong coupling of the electron transfer system to ATP synthesis. Limited uncoupling can reduce tissue oxidative stress, whereas inhibiting the uncoupling leads to increased mitochondrial membrane potential with greater mitochondrial ROS production [44-46]. $\mathrm{H}_{2} \mathrm{~S}$ can serve as a direct scavenger of ROS and peroxynitrite [47, 48], whereas cysteine is a key substrate for glutathione production, an important cellular antioxidant, and cysteine deficiency has been reported to be associated with increased oxidative stress [49]. This is reflected in the significant inverse relationship between CSE expression and nitrotyrosine formation observed in this study (Fig. 4).

The intersection of mitochondrial biogenesis, ROS generation, and inflammatory responses has been shown to be relevant in disease [50]. TNF $\alpha$ and IL-6 are recognized early players in the clinical response to sepsis and shown to be locally produced by intrinsic kidney cells in the early phase of injury $[51,52]$. Elevated serum levels of IL-6 were shown to be indicators of animals that developed AKI, in a rat cecal ligation puncture model, in contrast to those that did not develop AKI, and the increased IL-6 preceded evidence of morphological kidney injury [53]. Our findings of elevated TNF $\alpha$ and IL-6 levels in sepsis-induced AKI (Additional file 1: Table S2) are consistent with these reports.

Mitochondrial dysfunction caused by or coinciding with inflammation may contribute to metabolic derangement of $\mathrm{O}_{2}$ utilization in septic AKI. Recent animal studies [2, 54] as well as the $\mathrm{O}_{2}$ saturation levels reported here (Additional file 1: Table S2) suggest that septic AKI is not necessarily due to the reduced tissue oxygen availability but rather due to the deranged cellular $\mathrm{O}_{2}$ metabolism, as suggested by the hyperlactatemia, metabolic acidosis, and reduced mitochondrial activity (Additional file 1: Table S2 and Fig. 2b). Recently, it has been shown that in sepsis, activated immune cells switch their cellular metabolism from oxidative phosphorylation to glycolysis (Warburg effect), even if oxygen is abundant $[55,56]$. The reduced activity of complex II suggests the loss of mitochondrial "reserve capacity" in the kidneys of septic pigs in this study. Normally, mitochondria can make use of a "reserve capacity" in situations of increased energy demands by increasing complex II activity in response to enhanced glucose oxidation 
[57]. Hyperlactatemic patients suffering from septic shock have been reported to have increased lactate production concomitant to increased glucose turnover which is also reflected in this atherosclerotic septic pig model [58]. Interestingly, although the co-morbid septic pigs had increased glucose turnover overall, blood glucose levels did not differ from the sham group (Fig. 1), suggesting that the septic group was unable to mount an "adaptive" hyperglycemic stress response. This might be related to the reduced kidney CSE expression, as $\mathrm{CSE}^{-/-}$mice have been previously shown to have reduced rates of gluconeogenesis [12].

At first glance, this might be counterintuitive, since in comparison to the septic group, the sham animals with maintained kidney CSE levels had lower glucose rate of appearance (Fig. 1 and 3c). However, these animals did not need to increase glucose turnover as a stress response and had very low rates of catecholamine administration compared to septic animals (Additional file 1: Table S1). Considering previous results from our group in a sepsis study in non-co-morbid young pigs, which displayed two times higher rates of glucose appearance [59], atherosclerotic pigs in this study seem to fail in their stress-related upregulation of gluconeogenesis. The kidney can account for $25-40 \%$ of all glucose released into the circulation and thus plays an important role in glucose homeostasis $[6,60,61]$, especially under conditions of catecholamine treatment. Lactate is the predominant precursor for gluconeogenesis in healthy subjects stimulated with epinephrine to simulate physiological stress [60]. Increased lactate without hyperglycemia could be interpreted as a state wherein the body was no longer able to generate a hyperglycemic adaptive response to stress [6]. Pertinent to the current findings is the strong relation that was reported with regard to hyperlactatemia and "concomitant relative 'normoglycemia" and its association with the development of AKI [6]. Nonetheless, a limitation to the study is that we cannot discriminate how the higher norepinephrine infusion rates affected glucose metabolism, reduced CSE expression, and contributed to the more pronounced kidney dysfunction or if they simply reflected the severity of the disease in the individual animals.

\section{Conclusions}

To the best of our knowledge, this is the first report of a relation between CSE expression, renal tissue mitochondrial function, and the severity of AKI in a clinically relevant resuscitated large animal model of polymicrobial sepsis. AKI was correlated with the reduced CSE and PGC1 $\alpha$ expression, decreased mitochondrial respiratory activity concomitant with increased barrier dysfunction, increased oxidative stress, and metabolic acidosis which, combined, manifested in an inability of the cells to utilize oxygen [62]. Consequently, maintenance of CSE expression and endogenous $\mathrm{H}_{2} \mathrm{~S}$ availability might attenuate sepsis-induced metabolic alterations [8, 20, 63].

\section{Additional file}

Additional file 1: (DOCX $86 \mathrm{~kb})$

\section{Abbreviations}

AKI: Acute kidney injury; $\mathrm{CO}_{2}$ : Carbon dioxide; $\mathrm{CrCl}$ : Creatinine clearance; CSE: Cystathionine-y-lyase; CVP: Central venous pressure; ETS: Electron transfer system; FBM: Familial hypercholesterolemia Bretoncelles Meishan; FCCP: Carbonyl cyanide-p-trifluoromethoxyphenylhydrazone; $\mathrm{H}_{2} \mathrm{~S}$ : Hydrogen sulfide; HR: Heart rate; IL-6: Interleukin 6; MAP: Mean arterial pressure; NGAL: Neutrophil gelatinase-associated lipocalin; NO: Nitric oxide; NoA: Noradrenaline; OxPhos: Oxidative 
phosphorylation; PAOP: Pulmonary artery occlusion pressure; PEEP: Positive end-expiratory pressure; PGC1a: Peroxisome proliferator-activated receptor gamma coactivator 1-a; RNS: Reactive nitrogen species; ROS: Reactive oxygen species; TNFa: Tumor necrosis factor a

\section{Acknowledgements}

The authors would like to thank Rosy Engelhardt for the skillful technical assistance.

\section{Funding}

This study has been funded by the German Research Foundation (DFG, CRC1149 PR) and Ulm University (Baustein Programm BN).

\section{Authors' contributions}

TM performed the immunohistochemistry, data analysis and interpretation, and drafting of the manuscript. MW and BN performed the animal experiments and collected the data. JV and EC contributed to the data analysis. RW, CS, and PR conceived the study, helped with the data interpretation, and critically reviewed the manuscript. OM contributed to the experimental design, quantification of immunohistochemistry, data interpretation, and drafting of the manuscript. All authors read and approved the final manuscript.

\section{Ethics approval}

This is a post hoc study of material available from previous experiments that were performed in adherence to the National Institutes of Health Guidelines on the Use of Laboratory Animals and the European Union "Directive 2010/63 EU on the protection of animals used for scientific purposes" and authorized by the federal authorities for animal research of the Regierungspräsidium Tübingen (approved animal experimentation number: 1024), Baden-Württemberg, Germany, and the Animal Care Committee of the University of Ulm, Baden-Württemberg, Germany.

\section{Consent for publication}

Not applicable.

\section{Competing interests}

The authors declare that they have no competing interests.

\section{Publisher's Note}

Springer Nature remains neutral with regard to jurisdictional claims in published maps and institutional affiliations.

\section{Author details}

${ }^{1}$ Institut für Anästhesiologische Pathophysiologie und Verfahrensentwicklung, Universitätsklinikum Ulm, Helmholtzstrasse 8-1, 89081 Ulm, Germany. ${ }^{2}$ Klinik für Anästhesiologie, Universitätsklinikum Ulm, Ulm, Germany. ${ }^{3}$ Department of Biology, Laurentian University, Sudbury, ON, Canada. ${ }^{4}$ Department of Anesthesiology, The University of Texas Medical Branch at Galveston, 601 Harborside Drive, Galveston, TX 77555, USA. ${ }^{5}$ Department of Oncology, Microbiology and Immunology, Faculty of Science and Medicine, University of Fribourg, Fribourg, Switzerland.

Received: 13 June 2018 Accepted: 7 October 2018

Published online: 20 October 2018

\section{References}

1. Stenzel T, Weidgang C, Wagner K, Wagner F, Gröger M, Weber S, Stahl B, Wachter U, Vogt JA, Calzia E, Denk S, Georgieff M, Huber-Lang M, Radermacher P, McCook O (2016) Association of kidney tissue barrier disrupture and renal dysfunction in resuscitated murine septic shock. Shock 46:398-404. https://doi.org/10.1097/SHK.0000000000000599

2. Maiden MJ, Otto S, Brealey JK, Finnis ME, Chapman MJ, Kuchel TR, Nash CH, Edwards J, Bellomo R (2016) Structure and function of the kidney in septic shock. A prospective controlled experimental study. Am J Respir Crit Care Med 194:692700. https://doi.org/10.1164/rccm.201511-22850C

3. Doi K (2016) Role of kidney injury in sepsis. J Intensive Care 4:17. https://doi.org/10.1186/s40560-016-0146-3

4. Benes J, Chvojka J, Sykora R, Radej J, Krouzecky A, Novak I, Matejovic M (2011) Searching for mechanisms that matter in early septic acute kidney injury: an experimental study. Crit Care 15:R256. https://doi.org/10.1186/cc10517

5. Takasu O, Gaut JP, Watanabe E, To K, Fagley RE, Sato B, Jarman S, Efimov IR, Janks DL, Srivastava A, Bhayani SB, Drewry A, Swanson PE, Hotchkiss RS (2013) Mechanisms of cardiac and renal dysfunction in patients dying of sepsis. Am J Respir Crit Care Med 187:509-517. https://doi.org/10.1164/rccm.201211-19830C

6. Freire Jorge P, Wieringa N, de Felice E, van der Horst ICC, Oude Lansink A, Nijsten MW (2017) The association of early combined lactate and glucose levels with subsequent renal and liver dysfunction and hospital mortality in critically ill patients. Crit Care 21:218. https://doi.org/10.1186/s13054-017-1785-Z

7. Brealey D, Brand M, Hargreaves I, Heales S, Land J, Smolenski R, Davies NA, Cooper CE, Singer M (2002) Association between mitochondrial dysfunction and severity and outcome of septic shock. Lancet 360:219-223. https://doi.org/10. 1016/S0140-6736(02)09459-X

8. Merz T, Vogt JA, Wachter U, Calzia E, Szabo C, Wang R, Radermacher P, McCook O (2017) Impact of hyperglycemia on cystathionine- $\gamma$-lyase expression during resuscitated murine septic shock. Intensive Care Med Exp 5:30. https://doi.org/ 10.1186/s40635-017-0140-7

9. McCook O, Radermacher P, Volani C, Asfar P, Ignatius A, Kemmler J, Möller P, Szabó C, Whiteman M, Wood ME, Wang R, Georgieff M, Wachter U (2014) $\mathrm{H}_{2} \mathrm{~S}$ during circulatory shock: some unresolved questions. Nitric Oxide 41:48-61. https:// doi.org/10.1016/j.niox.2014.03.163 
10. Knöller E, Stenzel T, Broeskamp F, Hornung R, Scheuerle A, McCook O, Wachter U, Vogt JA, Matallo J, Wepler M, Gässler H, Gröger M, Matejovic M, Calzia E, Lampl L, Georgieff M, Möller P, Asfar P, Radermacher P, Hafner S (2016) Effects of hyperoxia and mild therapeutic hypothermia during resuscitation from porcine hemorrhagic shock. Crit Care Med 44(5): e264-e277. https://doi.org/10.1097/CCM.0000000000001412

11. Bos EM, Wang R, Snijder PM, Boersema M, Damman J, Fu M, Moser J, Hillebrands JL, Ploeg RJ, Yang G, Leuvenink HG, van Goor H (2013) Cystathionine $\gamma$-lyase protects against renal ischemia/reperfusion by modulating oxidative stress. J Am Soc Nephrol 24:759-770. https://doi.org/10.1681/ASN.2012030268

12. Untereiner AA, Wang R, Ju Y, Wu L (2016) Decreased gluconeogenesis in the absence of cystathionine gamma-lyase and the underlying mechanisms. Antioxid Redox Signal 24:129-140. https://doi.org/10.1089/ars.2015.6369

13. Parikh SM (2013) Therapeutic targeting of the mitochondrial dysfunction in septic acute kidney injury. Curr Opin Crit Care 19:554-559. https://doi.org/10.1097/MCC.0000000000000038

14. Hartmann C, Nussbaum B, Calzia E, Radermacher P, Wepler M (2017) Gaseous mediators and mitochondrial function: the future of pharmacologically induced suspended animation? Front Physiol 8:691. https://doi.org/10.3389/fphys.2017.00691

15. Aslami H, Pulskens WP, Kuipers MT, Bos AP, van Kuilenburg AB, Wanders RJ, Roelofsen J, Roelofs JJ, Kerindongo RP, Beurskens CJ, Schultz MJ, Kulik W, Weber NC, Juffermans NP (2013) Hydrogen sulfide donor NaHS reduces organ injury in a rat model of pneumococcal pneumosepsis, associated with improved bio-energetic status. PLoS One 8:e63497. https://doi.org/10.1371/journal.pone.0063497

16. Aslami H, Beurskens CJ, de Beer FM, Kuipers MT, Roelofs JJ, Hegeman MA, Van der Sluijs KF, Schultz MJ, Juffermans NP (2013) A short course of infusion of a hydrogen sulfide-donor attenuates endotoxemia induced organ injury via stimulation of anti-inflammatory pathways, with no additional protection from prolonged infusion. Cytokine 61:614-621. https://doi.org/10.1016/j.cyto.2012.11.018

17. Li L, Bhatia M, Zhu YZ, Zhu YC, Ramnath RD, Wang ZJ, Anuar FB, Whiteman M, Salto-Tellez M, Moore PK (2005) Hydrogen sulfide is a novel mediator of lipopolysaccharide-induced inflammation in the mouse. FASEB J 19:1196-1198. https://doi.org/10.1096/fj.04-3583fje

18. Angus DC, Linde-Zwirble WT, Lidicker J, Clermont G, Carcillo J, Pinsky MR (2001) Epidemiology of severe sepsis in the United States: analysis of incidence, outcome, and associated costs of care. Crit Care Med 29:1303-1310

19. Nußbaum BL, McCook O, Hartmann C, Matallo J, Wepler M, Antonucci E, Kalbitz M, Huber-Lang M, Georgieff M, Calzia E, Radermacher P, Hafner S (2016) Left ventricular function during porcine resuscitated septic shock with pre-existing atherosclerosis. Intensive Care Med Exp. 4:14. https://doi.org/10.1186/s40635-016-0089-y

20. Merz T, Stenzel T, Nußbaum B, Wepler M, Szabo C, Wang R, Radermacher P, McCook O (2017) Cardiovascular disease and resuscitated septic shock lead to the downregulation of the H2S-producing enzyme cystathionine- $y-$ lyase in the porcine coronary artery. Intensive Care Med Exp. 5:17. https://doi.org/10.1186/s40635-017-0131-8

21. Thim T, Hagensen MK, Drouet L, Bal Dit Sollier C, Bonneau M, Granada JF, Nielsen LB, Paaske WP, Bøtker HE, Falk E (2010) Familial hypercholesterolaemic downsized pig with human-like coronary atherosclerosis: a model for preclinical studies. Eurolntervention 6:261-268

22. Thim T (2010) Human-like atherosclerosis in minipigs: a new model for detection and treatment of vulnerable plaques. Dan Med Bull 57:B4161

23. Matějková Š, Scheuerle A, Wagner F, McCook O, Matallo J, Gröger M, Seifritz A, Stahl B, Vcelar B, Calzia E, Georgieff M, Möller P, Schelzig H, Radermacher P, Simon F (2013) Carbamylated erythropoietin-FC fusion protein and recombinant human erythropoietin during porcine kidney ischemia/reperfusion injury. Intensive Care Med 39:497-510. https://doi. org/10.1007/s00134-012-2766-y

24. Kawashima S, Yokoyama M (2004) Dysfunction of endothelial nitric oxide synthase and atherosclerosis. Arterioscler Thromb Vasc Biol 24:998-1005. https://doi.org/10.1161/01.ATV.0000125114.88079.96

25. Aminzadeh MA, Vaziri ND (2012) Downregulation of the renal and hepatic hydrogen sulfide (H2S)-producing enzymes and capacity in chronic kidney disease. Nephrol Dial Transplant 27:498-504. https://doi.org/10.1093/ $\mathrm{ndt} / \mathrm{gfr} 560$

26. Wepler M, Hafner S, Scheuerle A, Reize M, Gröger M, Wagner F, Simon F, Matallo J, Gottschalch F, Seifritz A, Stahl B, Matejovic M, Kapoor A, Möller P, Calzia E, Geogieff M, Wachter U, Vogt JA, Thiemermann C, Radermacher P, McCook O (2013) Effects of the PPAR- $\beta / \delta$ agonist GW0742 during resuscitated porcine septic shock. Intensive Care Med Exp. 1:28. https://doi.org/10.1186/2197-425X-1-9

27. Simon F, Scheuerle A, Gröger M, Stahl B, Wachter U, Vogt J, Speit G, Hauser B, Möller P, Calzia E, Szabó C, Schelzig H, Georgieff M, Radermacher P, Wagner F (2011) Effects of intravenous sulfide during porcine aortic occlusion-induced kidney ischemia/reperfusion injury. Shock 35:156-163. https://doi.org/10.1097/SHK.0b013e3181f0dc91

28. Barth E, Bassi G, Maybauer DM, Simon F, Gröger M, Oter S, Speit G, Nguyen CD, Hasel C, Möller P, Wachter U, Vogt JA, Matejovic M, Radermacher P, Calzia E (2008) Effects of ventilation with 100\% oxygen during early hyperdynamic porcine fecal peritonitis. Crit Care Med 36:495-503. https://doi.org/10.1097/01.CCM.0B013E318161FC45

29. Simmons MN, Brandina R, Hernandez AV, Gill IS (2010) Surgical management of bilateral synchronous kidney tumors: functional and oncological outcomes. J Urol 184:865-872. https://doi.org/10.1016/j.juro.2008.03.022

30. Lieberthal W, Nigam SK (2000) Acute renal failure. II. Experimental models of acute renal failure: imperfect but indispensable. Am J Physiol Renal Physiol 278:F1-F12. https://doi.org/10.1152/ajprenal.2000.278.1.F1

31. Venter DJ, Tuzi NL, Kumar S, Gullick WJ (1987) Overexpression of the c-erbB-2 oncoprotein in human breast carcinomas: immunohistological assessment correlates with gene amplification. Lancet 2:69-72

32. Podhajsky RJ, Bidanset DJ, Caterson B, Blight AR (1997) A quantitative immunohistochemical study of the cellular response to crush injury in optic nerve. Exp Neurol 143:153-161

33. Dias P, Chen B, Dilday B, Palmer H, Hosoi H, Singh S, Wu C, Li X, Thompson J, Parham D, Qualman S, Houghton P (2000) Strong immunostaining for myogenin in rhabdomyosarcoma is significantly associated with tumors of the alveolar subclass. Am J Pathol 156:399-408. https://doi.org/10.1016/50002-9440(10)64743-8

34. Baumgart K, Wagner F, Gröger M, Weber S, Barth E, Vogt JA, Wachter U, Huber-Lang M, Knöferl MW, Albuszies G, Georgieff M, Asfar P, Szabó C, Calzia E, Radermacher P, Simkova V (2010) Cardiac and metabolic effects of hypothermia and inhaled hydrogen sulfide in anesthetized and ventilated mice. Crit Care Med 38:588-595. https://doi.org/10.1097/ CCM.0b013e3181b9ed2e 
35. Hartmann C, Loconte M, Antonucci E, Holzhauser M, Hölle T, Katzsch D, Merz T, McCook O, Wachter U, Vogt JA, Hoffmann A, Wepler M, Gröger M, Matejovic M, Calzia E, Georgieff M, Asfar P, Radermacher P, Nussbaum BL (2017) Effects of hyperoxia during resuscitation from hemorrhagic shock in swine with preexisting coronary artery disease. Crit Care Med 45:e1270-e1279. https://doi.org/10.1097/CCM.0000000000002767

36. Parikh SM, Yang Y, He L, Tang C, Zhan M, Dong Z (2015) Mitochondrial function and disturbances in the septic kidney. Semin Nephrol 35:108-119. https://doi.org/10.1016/.jsemnephrol.2015.01.011

37. Yuan Y, Huang S, Wang W, Wang Y, Zhang P, Zhu C, Ding G, Liu B, Yang T, Zhang A (2012) Activation of peroxisome proliferator-activated receptor- $y$ coactivator $1 a$ ameliorates mitochondrial dysfunction and protects podocytes from aldosterone-induced injury. Kidney Int 82:771-789. https://doi.org/10.1038/ki.2012.188

38. Müller-Deile J, Schiffer M (2014) The podocyte power-plant disaster and its contribution to glomerulopathy. Front Endocrinol (Lausanne) 5:209. https://doi.org/10.3389/fendo.2014.00209

39. Emma F, Montini G, Parikh SM, Salviati L (2016) Mitochondrial dysfunction in inherited renal disease and acute kidney injury. Nat Rev Nephrol 12:267-280. https://doi.org/10.1038/nrneph.2015.214

40. Saleem MA (2015) One hundred ways to kill a podocyte. Nephrol Dial Transplant 30:1266-1271. https://doi.org/ $10.1093 / \mathrm{ndt} / \mathrm{gfu} 63$

41. Brownlee M (2005) The pathobiology of diabetic complications: a unifying mechanism. Diabetes 54:1615-1625

42. Huang G, Chen Y, Lu H, Cao X (2007) Coupling mitochondrial respiratory chain to cell death: an essential role of mitochondrial complex I in the interferon-beta and retinoic acid-induced cancer cell death. Cell Death Differ 14: 327-337. https://doi.org/10.1038/sj.cdd. 4402004

43. Teng RJ, Wu TJ, Afolayan AJ, Konduri GG (2016) Nitrotyrosine impairs mitochondrial function in fetal lamb pulmonary artery endothelial cells. Am J Physiol Cell Physiol 310:C80-C88. https://doi.org/10.1152/ajpcell.00073.2015

44. Nègre-Salvayre A, Hirtz C, Carrera G, Cazenave R, Troly M, Salvayre R, Pénicaud L, Casteilla L (1997) A role for uncoupling protein-2 as a regulator of mitochondrial hydrogen peroxide generation. FASEB J 11:809-815

45. Caldeira da Silva CC, Cerqueira FM, Barbosa LF, Medeiros MH, Kowaltowski AJ (2008) Mild mitochondrial uncoupling in mice affects energy metabolism, redox balance and longevity. Aging Cell 7:552-560. https://doi.org/10.1111/j. 1474-9726.2008.00407.x

46. Zorov DB, Juhaszova M, Sollott SJ (2014) Mitochondrial reactive oxygen species (ROS) and ROS-induced ROS release. Physiol Rev 94:909-950. https://doi.org/10.1152/physrev.00026.2013

47. Whiteman M, Armstrong JS, Chu SH, Jia-Ling S, Wong BS, Cheung NS, Halliwell B, Moore PK (2004) The novel neuromodulator hydrogen sulfide: an endogenous peroxynitrite 'scavenger'? J Neurochem 90:765-768. https://doi.org/ 10.1111/j.1471-4159.2004.02617.x

48. Kimura Y, Goto Y, Kimura H (2010) Hydrogen sulfide increases glutathione production and suppresses oxidative stress in mitochondria. Antioxid Redox Signal 12:1-13. 10.1089=ars.2008.2282

49. Dröge W (2005) Oxidative stress and ageing: is ageing a cysteine deficiency syndrome? Philos Trans R Soc Lond Ser B Biol Sci 360:2355-2372. https://doi.org/10.1098/rstb.2005.1770

50. Cherry AD, Piantadosi CA (2015) Regulation of mitochondrial biogenesis and its intersection with inflammatory responses. Antioxid Redox Signal 22:965-976. https://doi.org/10.1074/jbc.M113.512483

51. Schrier RW (2002) Cancer therapy and renal injury. J Clin Invest 110:743-745. https://doi.org/10.1172/JCI200216568

52. Su H, Lei CT, Zhang C (2017) Interleukin-6 signaling pathway and its role in kidney disease: an update. Front Immunol 8 : 405. https://doi.org/10.3389/fimmu.2017.00405

53. Chawla LS, Seneff MG, Nelson DR, Williams M, Levy H, Kimmel PL, Macias WL (2007) Elevated plasma concentrations of IL-6 and elevated APACHE II score predict acute kidney injury in patients with severe sepsis. Clin J Am Soc Nephrol 2: 22-30. https://doi.org/10.2215/CJN.02510706

54. van Niekerk G, Davis T, Engelbrecht AM (2017) Hyperglycaemia in critically ill patients: the immune system's sweet tooth. Crit Care 21:202. https://doi.org/10.1186/s13054-017-1775-1

55. Ferreira LM (2010) Cancer metabolism: the Warburg effect today. Exp Mol Pathol 89(3):372-380. https://doi.org/10.1016/ j.yexmp.2010.08.006

56. Liu X, Wu SJ, Fang XM (2017) Insight into the glucose metabolism of immune cells in sepsis. J Anesth Perioper 4(1):3844. https://doi.org/10.24015/JAPM.2017.0005

57. Pfleger J, He M, Abdellatif M (2015) Mitochondrial complex II is a source of the reserve respiratory capacity that is regulated by metabolic sensors and promotes cell survival. Cell Death Dis 6:e1835. https://doi.org/10.1038/cddis. 2015.202

58. Revelly JP, Tappy L, Martinez A, Bollmann M, Cayeux MC, Berger MM, Chioléro RL (2005) Lactate and glucose metabolism in severe sepsis and cardiogenic shock. Crit Care Med 33:2235-2240. https://doi.org/10.1097/01.CCM. $0000181525.99295 .8 \mathrm{~F}$

59. Simon F, Giudici R, Scheuerle A, Gröger M, Asfar P, Vogt JA, Wachter U, Ploner F, Georgieff M, Möller P, Laporte R, Radermacher P, Calzia E, Hauser B (2009) Comparison of cardiac, hepatic, and renal effects of arginine vasopressin and noradrenaline during porcine fecal peritonitis: a randomized controlled trial. Crit Care 13:R113. https://doi.org/10.1186/cc7959

60. Stumvoll M, Meyer C, Mitrakou A, Nadkarni V, Gerich JE (1997) Renal glucose production and utilization: new aspects in humans. Diabetologia 40:749-757. https://doi.org/10.1007/s001250050745

61. Gerich JE, Meyer C, Woerle HJ, Stumvoll M (2011) Renal gluconeogenesis: its importance in human glucose homeostasis. Diabetes Care 24:382-391

62. Arulkumaran N, Pollen S, Greco E, Courtneidge H, Hall AM, Duchen MR, Tam FWK, Unwin RJ, Singer M (2018) Renal tubular cell mitochondrial dysfunction occurs despite preserved renal oxygen delivery in experimental septic acute kidney injury. Crit Care Med 46(4):e318-e325. https://doi.org/10.1097/CCM.0000000000002937

63. Suzuki K, Olah G, Modis K, Coletta C, Kulp G, Gerö D, Szoleczky P, Chang T, Zhou Z, Wu L, Wang R, Papapetropoulos A, Szabo C (2011) Hydrogen sulfide replacement therapy protects the vascular endothelium in hyperglycemia by preserving mitochondrial function. Proc Natl Acad Sci U S A 108:13829-13834. https://doi.org/10.1073/pnas.1105121108 